\title{
FENÔMENO HISTÉRICO OU PSICOSSOMÁtICO? RE-LENDO O HOMEM DOS LOBOS COM WINNICOTT
}

\author{
Nadja Nara Barbosa Pinheiro \\ Maria Vitória Mamede Maia ${ }^{\star}$
}

\begin{abstract}
RESUMO
O objetivo é o de produzirmos uma reflexão teórica sobre os adoecimentos psicossomáticos que nos permita enfrentar seus impasses clínicos tomando como referências Freud e Winnicott. O estudo da angústia como afeto que funda as relações soma/psique nos levou ao estudo da Histeria de Angústia trabalhada, por Freud, no caso clínico do Homem dos Lobos, onde as afecções intestinais foram entendidas como um fenômeno histérico. Propomos sobrepor a essa hipótese que podemos entendê-las, também, como um adoecimento psicossomático como Winnicott o concebe: uma defesa psíquica diante de um movimento de des-integração das malhas psicossomáticas. Destaca-se que encontramos nos autores fundamentos teórico/clínicos para as afecções psicossomáticas.
\end{abstract}

Palavras-chave: afecção psicossomática; clínica psicanalítica; angústia; psiquel soma; histeria de angústia.

\section{HYSTERICAL OR PSYCHOSSOMATIC PHENOMENOM? RE-READING THE MAN OF WOLVES WITH WINNICOTT}

\begin{abstract}
The objective is to achieve a theoretical understanding of the psychosomatic illness by taking as references Freud and Winnicott. The study of anguish led us to study the Hysteria of Anguish worked in the case of the "Man of Wolves" in which intestinal disorders were taken as a hysterical phenomenon. We are proposing that we can also understand this disease as a psychosomatic illness as Winnicott designs it: as a psychic defense against a movement of de-integration of the psychosomatic nets. Our propose is to point out that we found in both fundaments to theoretical understanding and clinical conduction of psychosomatic disorders.
\end{abstract}

Keywords: psychosomatic illness; psychoanalytical clinic; anguish; psycho/ soma; hysteria of anguish.

\footnotetext{
^ Psicóloga, Mestre e Doutora em Psicologia, Professora da Graduação e do Mestrado em Psicologia da Universidade Federal do Paraná. Coordenadora do laboratório de Psicanálise da Universidade Federal do Paraná. Endereço: Rua XV de novembro, 1299 - Centro - Curitiba. CEP: 80060000.

E-mail: nadjanbp@ufpr.br

$\star \star$ Psicóloga, Mestre em Literatura e Doutora em Psicologia, Professora do Departamento de Educação da Universidade Federal do Rio de Janeiro. End: Av. Pasteur, 250 - Praia Vermelha Rio de Janeiro. CEP 22290902.

E-mail: mariavitoriamaia@ufrj.br
} 


\section{INTRODUÇÃO}

O presente trabalho se insere em um projeto de pesquisa que vem sendo desenvolvido no âmbito de uma Universidade Federal, cuja proposta nasceu do encontro, em nossa clínica cotidiana, com um tipo de adoecimento bastante peculiar: as afecções que se expressam por meio de adoecimentos corporais. Especificamos que não se trata aqui das conversões histéricas, ricas em significados simbólicos e, por isso mesmo, bastante adequadas ao processo clínico oferecido pela psicanálise. Ao contrário, os adoecimentos que aqui destacamos se referem àqueles que, ao se expressarem por meio da corporeidade, trazem como marca a inacessibilidade da linguagem e um profundo silêncio em relação à possibilidade de alcançarem alguma significação simbólica, desafiando, sobremaneira, nossos esforços clínicos.

Portando tais características, acreditamos que esses adoecimentos evidenciam a aspereza das relações soma/psique na medida em que essas indicam a (im) possível tarefa de habitarmos um corpo que se organiza a partir de ordens distintas e estranhas entre si: ordem orgânica e ordem lingüística, que se implicam e se transformam sem, no entanto, chegarem a uma complementaridade ou ajuste. $\mathrm{O}$ que gostaríamos de pontuar aqui é o fato de essas afecções colocarem em cheque a clínica psicanalítica que se vê, então, impelida a operar um esforço em alargar seus horizontes tanto teóricos quanto clínicos.

Foi com esse objetivo que iniciamos uma investigação sistematizada nas obras de Freud e Winnicott procurando encontrar nesses autores um referencial conceitual sobre as relações psique/soma que nos permitisse encontrar uma maior sustentação clínica. Nesse intento, tomamos como via de acesso, o conceito de angústia posto que, em ambos os autores, este é o afeto que resta das articulações estabelecidas entre soma e psiquê e a partir do qual uma resposta pode ser oferecida no caminho à construção da subjetividade.

Traremos, no presente artigo, um recorte nessa nossa trajetória. Inicialmente procuraremos inserir o leitor no espaço temático freudiano sobre o conceito de angústia, privilegiando quais foram as tensões presentes, as dificuldades encontradas, as saídas propostas e os fracassos absorvidos pelo autor em seus primeiros ensaios teórico/clínicos. Em seguida, apresentaremos o modo como Freud contornou um dos impasses clínicos impostos pela sensação de angústia por meio da construção de um novo quadro nosográfico: a histeria de angústia. Nesse contexto, traremos o caso clínico do homem dos lobos para propor uma novidade, isto é, para indicarmos como seria possível, recorrendo ao olhar winnicottiano, encontrar elementos que nos permitam sobrepor ao entendimento freudiano sobre o caso, uma compreensão a mais sobre os sintomas que seu paciente apresentava. Se, em sua leitura, Freud entende os adoecimentos intestinais de seu paciente como sendo da ordem histérica, nós propomos que eles podem, também, ser compreendidos como uma afecção psicossomática. Para tal, apresentamos, de forma sucinta, a perspectiva winnicottiana sobre esse tipo de patologia. Trajetória que nos permitirá concluir que, em ambos os autores, encontramos elementos básicos importantíssimos para lidarmos com as afecções que se expressam por meio do corpo que tanto nos desafiam em nosso ofício diário. 


\section{SOBRE A ANGÚSTIA, A FOBIA E A CLÍNICA: PRIMEIRAS CONSIDERAÇÕES}

É fácil perceber que no primeiro momento de constituição de sua obra, Freud pretendia, sobretudo, a construção de um quadro nosográfico que pudesse dar conta das variadas configurações das afecções mentais. Destacando que, em um primeiro referencial ainda médico, essas eram compreendidas por dois vieses: as que se pautavam em uma lesão organicamente determinada e as que se configuravam sobre lesões funcionais, essas últimas sendo denominadas de neuroses. Para compreender as neuroses, Freud (1976 [1895]) procurou evidenciar seus fundamentos etiológicos e desde muito cedo tentou circunscrevê-las no campo da sexualidade, fazendo subdividir a etiologia neurótica em dois patamares:

a) neuroses que se estabelecem a partir de uma desorganização da energia sexual somática adulta, ou seja, um curto-circuito na forma de organizar e dar vazão à essa energia que, em seu circuito "normal" deveria inundar o registro psíquico e conduzir à satisfação sexual. A essas patologias referentes a modos inadequados de conduzir a energia sexual somática Freud denomina de "Neuroses Atuais", por serem contemporâneas a idade adulta e por não trazerem um mecanismo psíquico em sua constituição.

b) em contraposição, o autor destaca um grupo de neuroses nos quais ele observa um mecanismo psíquico bastante atuante, em termos etiológicos, e que se referem a inúmeros entraves e dificuldades de se lidar com a energia sexual psíquica, e por isso mesmo denominadas pelo autor de "Psico-neuroses".

É nesse contexto que Freud circunscreve suas considerações iniciais a respeito das relações entre os campos somático e psíquico que se expressam, sobretudo, como impasses na clínica. Isso porque o autor se depara com a inadequação do método de tratamento por ele proposto para dar conta do resto que permeia a impossibilidade em precisar uma diferenciação exata entre os campos somáticos e psíquicos: a sensação de angústia. Tal sensação é tão evidente em seus pacientes que Freud se vê compelido a destacar, entre as neuroses atuais, uma patologia específica que ele denomina de "Neurose de Angústia" (FREUD,1976[1895]). Nesta, a energia sexual somática se vê impedida de alcançar o limiar psíquico e investir representações mentais. Não alçando o plano psíquico, a energia sexual somática, desvinculada de uma representação, se transforma em angústia, impactando o paciente em níveis distintos: subjetivamente por meio de uma sensação de fadiga, desânimo, desfalecimento; corporalmente, por meio de taquicardia, sudorese, respiração ofegante. Para lidar com todos esses efeitos, o paciente se vê compelido a produzir um movimento no qual ele possa contornar a sensação de angústia. A construção das fobias se apresenta como o mecanismo possível para lidar com essa energia sem representação transformada em angústia. Ao temer o objeto externo, o paciente aparentemente passa a controlar e evitar a invasão da angústia. Fazer desse processo o ponto inicial de um deslocamento incessante da energia desvinculada para dar conta de um possível ataque de angústia é comum. Ou seja, a construção de uma neurose obsessiva, a partir de uma neurose de angústia que se transformara em uma fobia é descrita, por Freud, como freqüente. (FREUD, 1976[1894]) 
Freud relaciona, nesse esquema, a angústia e a fobia à contemporaneidade da vida adulta, já que ambas se referem a uma neurose atual. Porém, o problema com o qual o autor se depara em seguida será o de entender a construção das fobias em uma criança. A primeira proposta freudiana para desvendar esse mistério foi inserir a fobia no seio de uma psico-neurose, posto que essas são constituídas na infância, forjando o conceito de "Histeria de angústia". Nesse contexto, o autor apresenta suas argumentações em dois textos exemplares, o "Pequeno Hans" (FREUD, 1976 [1909]) e o "Homem dos Lobos" (FREUD, 1976 [1918]). Em ambos, Freud supõe que passagem pelo complexo edipiano insere a necessidade de se produzir um mecanismo psíquico que dê conta dos desejos sexuais incestuosos. O mecanismo de recalque seria inserido nesse contexto justamente para tornar Inconsciente o que é da ordem do proibido e inaceitável. Entretanto o autor percebe que o recalque não é capaz de solucionar inteiramente os conflitos inerentes ao complexo de Édipo. O primeiro passo do processo de recalcamento produz uma separação entre representação e seu afeto correspondente. Em seguida, a representação é tornada inconsciente e a libido liberada permanece solta, sem vinculação na esfera consciente. Segundo o autor, essa libido desvinculada é transformada em angústia. Tanto em Hans quanto no Homem dos Lobos, Freud supõe que o destino encontrado por ambos para dar conta da libido liberada pós-recalcamento e sentida como angústia tenha sido o endereçamento desta a um objeto externo: o cavalo, no caso de Hans, ou o lobo, no caso do homem dos lobos. Manter-se longe dos animais temidos manteria ambos os meninos livres de novos ataques súbitos de angústia.

Percebemos, então, que nesse novo arranjo teórico, Freud relaciona a angústia e a fobia com o mecanismo fundamental de uma psico-neurose, ou seja, relaciona ao recalcamento e a histeria. Tal proposição teórica sobre a histeria de angústia lhe permite compreender inúmeros sintomas apresentados pelo homem dos lobos como sendo de cunho histérico. Entre esses, destacamos sua compreensão sobre os problemas intestinais apresentados por seu paciente, pois acreditamos que nestes reside uma interessante questão. Com o objetivo de tentarmos entender esses mesmos sintomas como referentes a uma questão não exclusivamente histérica, mas, igualmente, psicossomática, tal como Winnicott a concebe, apresentaremos, inicialmente, o caso clínico freudiano para depois passarmos às considerações de Winnicott sobre a construção do campo psicossomático sobre as quais sustentaremos nossos argumentos.

\section{O HOMEM DOS LOBOS DE FREUD}

O caso conhecido como "Homem dos Lobos", se refere a um rapaz que chega à análise com Freud depois de um longo período de adoecimento orgânico, uma gonorréia infecciosa. Segundo Freud, depois dessa moléstia o paciente cai em um adoecimento que se assemelha a uma depressão e o procura. Traz consigo uma longa história de internações psiquiátricas e um diagnóstico de bi-polaridade que é desconsiderado por Freud. Em sua perspectiva, Freud parte do princípio que se trata de complicações e desdobramentos de uma neurose infantil que à época se expressou por uma histeria de angústia, resultando em uma fobia animal. Em 
continuidade, a fobia se desdobra em uma neurose obsessiva de cunho religioso que perdurou até seus 10 anos de idade. Sobre o momento de erupção da doença neurótica o paciente pouco sabe. Recorda-se apenas que até um dado momento de sua vida era um menino muito disciplinado e que de repente se transformou, apresentando comportamentos agressivos e indisciplinados que a todos espantou. Recorda-se também de fases em que sentiu muito medo. Inicialmente tinha muito medo de um lobo que vira em um livro e, posteriormente, de lagartas e besouros. Curiosamente, alternava o medo com momentos em que maltratava e cortava as lagartas e os besouros em pedacinhos.

Após esse período de rebeldia, sadismo e fobia, sucedeu um longo período marcado por rituais obsessivos nos quais o paciente se via obrigado a rezar muito e fazer um número incomensurável de sinais da cruz. Esse segundo momento também foi marcado pela ambivalência, pois ao lado de toda a reverência religiosa, o paciente era assaltado por pensamentos blasfêmicos, tais como, "deus-merda" ou "deus-suíno". Desenvolveu uma relação com o pai extremamente insatisfatória e competitiva baseada no medo até que todos esses sintomas desapareceram por influência dos tutores masculinos que substituíram as mulheres em sua educação.

$\mathrm{Na}$ análise do caso, Freud tenta entender essa sucessão de fenômenos tomando como referência a sua teoria sobre a constituição subjetiva a partir das organizações da sexualidade. Assim, Freud inicia sua análise focando a mudança de comportamento do menino relacionando-a com uma provável ameaça de castração proferida pelas pessoas que dele cuidavam. O paciente lembra-se, então, de que a irmã o havia induzido a práticas sexuais quando eram ainda bem pequenos. Nessas vivências ele tomava um posicionamento passivo que procurou compensar com uma série de fantasias nas quais era ele quem tomava a atitude ativa em relação à irmã. A partir de um dado momento, o paciente responde às seduções da irmã com uma recusa e passa a endereçar suas investidas sexuais à sua babá, masturbando-se em sua frente. Comportamento veementemente repreendido pela babá que o ameaça dizendo que se ele continuar a se masturbar uma ferida nascerá no lugar de seu pênis. $\mathrm{O}$ menino, então, responde à essa ameaça de castração, por um lado, negando sua possibilidade de ocorrência e por outro com uma regressão em seu desenvolvimento sexual. A fase fálica em que se posicionava, cede espaço ao retorno à fase anal/sádica que o impele à produção de inúmeras atividades que oscilam entre o sadismo (atormentar a babá e matar animaizinhos) e o masoquismo (fantasias de ser espancado e corporalmente castigado). Para Freud, a regressão da libido foi acompanhada por uma substituição de sua escolha objetal (babá) pela identificação anterior (o pai) permitindo uma confluência entre os objetos da identificação e da escolha objetal que passou a ser o mesmo (pai). Assim, o comportamento insubordinado do menino servia a seus propósitos: masoquistamente ao ser castigado, obtinha do pai a satisfação sexual que ansiava e, simultaneamente, expiava sua culpa pelo desejo incestuoso em relação ao pai.

Interessa observar que até então, a angústia ainda não se fizera presente e só o fará após uma produção onírica que atuará como um trauma externo. O sonho a que se refere Freud é o famoso sonho no qual sete lobos dispostos em cima de uma árvore fitam estranhamente o paciente. Por meio de inúmeras associações 
produzidas em análise, Freud foi capaz de relacionar o sonho com uma provável cena observada pelo paciente em sua mais tenra infância. Segundo Freud, o sonho teve o caráter de produzir, em um momento posterior, a re-configuração e re-ordenação do que fora observado pelo paciente mas não compreendido, posto que no momento lhe faltavam recursos psíquicos para tal. Construindo a cena primária com seu paciente, Freud supõe que esta girava em torno de inúmeras sensações e vivências em relação à sexualidade que culminou com a visão, pelo paciente, da cópula "a tergo" de seus pais. Isto significa, em uma posição que permitiu ao paciente observar os genitais da mãe e do pai, podendo assim relacioná-los às posições passiva e ativa em relação ao ato sexual. Segundo Freud, esta vivência ocorreu em um momento no qual o paciente se encontrava ainda em um período de completa identificação com a mãe. Deste fato resulta o anseio do paciente em estar em seu lugar e obter do pai a mesma satisfação sexual que sua mãe obtivera. Porem, para que tal ocorresse, o preço a ser pago pelo paciente seria o de perder o órgão sexual masculino e ser, como a mãe, castrado. Importa salientar que Freud deixa claro que tal conflito não se apresentou no momento em que o paciente vivenciou a cena, mas apenas no momento do sonho que o lançou no conflito ao oferecer um sentido à cena pretérita. É esse o caráter traumático do sonho aludido por Freud que ao remeter o paciente à cena primária o introduz no conflito ao fazer valer a ameaça de castração transformando o desejo de ser satisfeito pelo pai em puro medo de ser por ele castrado.

Diante do impasse estabelecido, a sexualidade do paciente, em organização, sofre múltiplos revezes pela percepção da possibilidade da castração como fato: o desejo por ser sexualmente satisfeito pelo pai é recalcado resultando na emergência da angústia que se expressa, por substituição, como medo do lobo. Nesse mecanismo específico de uma histeria de angústia que se desdobra em uma fobia, Freud enfatiza que aquilo que impulsionou o movimento de recalque foi o interesse narcísico do ego contra uma corrente sexual que para ser efetivada requeria a aceitação da castração.

\section{Do SONHO À CENA}

Pelo relato freudiano, sabemos que o paciente descreve, em análise, um sonho que o remete a um momento pretérito de sua vida, implicando-o na re-ordenação de vivências e experiências que permaneciam sem sentidos e significações. O interessante é que Freud destaca que, nesse movimento, algo se transforma e o paciente alcança um entendimento mais elaborado sobre essas vivências marcando o caráter transicional e elaborativo dos processos oníricos. Igualmente importante é o fato de Freud enfatizar também que a partir daí, dois modos de ordenação psíquica se superpõem. Por um lado, após o processo onírico produzir seus efeitos, alguns elementos permaneceram sendo organizados nos mesmos moldes de ordenação relativo ao estágio primitivo de desenvolvimento subjetivo. Por outro lado, em concomitância, alguns elementos sofreram um processo organizador pelos recursos psíquicos mais elaborados condizentes com a idade do paciente à época do sonho. Isto é, recursos simbólicos que permitiram que diante 
da ameaça de castração, o paciente tenha produzido uma solução neurótica como o recalque da corrente homossexual, por exemplo, decorrendo daí toda uma série de sintomas histéricos e obsessivos tais como os descritos por Freud no texto.

Mas, em nossa opinião, é importante demarcar que Freud sugere a possibilidade de que alguns elementos psíquicos permanecem aquém de uma ordenação simbólica e trarão, ao longo da vida do paciente, a marca dessa forma arcaica de organização condizente com o momento de constituição subjetiva do paciente ao presenciar a cena primária entre seus pais. Isto é, o que gostaríamos de destacar é que podemos perceber, também, com a descrição do caso, que tal modo de organização arcaica não se refere apenas aos momentos da cena e do sonho, mas se repete em inúmeros outros episódios da vida do paciente, marcando a necessidade de abandonarmos a idéia de uma organização subjetiva que se estabelece pela via desenvolvimentista, linear ou cronológica. Isto implica na probabilidade de nos defrontarmos com os estágios primitivos de nossa constituição subjetiva se faz sempre presente. Tal fenômeno se expressa no texto freudiano, por exemplo, em relação às complicações intestinais de seu paciente. No relato do autor, o vemos afirmar que esses problemas intestinais seriam afecções histéricas que o perseguem há anos. Sua hipótese é re-afirmada tanto por um especialista médico quanto pelo fato de os sintomas sofrerem alterações resultantes do trabalho de análise. Além disso, encontramos no texto inúmeros exemplos das articulações bem estabelecidas por Freud sobre as relações simbólicas entre fezes e dinheiro. Porém, vemos também que nem tudo em relação às complicações intestinais de seu paciente é solucionado. Um resíduo não compreendido e não abordado permanece presente na vida do paciente, adoecendo-o. Aqui, acreditamos que, tal como em Dora que Freud (1976 [1904]) afirmou que um sintoma histérico para se constituir depende de uma "complacência somática", no homem dos lobos isso também se aplica. Há, nas afecções intestinais do Homem dos Lobos, um resto somático a ser considerado.

Se não vejamos: Freud supõe que o paciente, ao visualizar a cena do coito dos pais, sem compreendê-la psiquicamente, inicialmente a sente como violenta e depois agradável. Reage a essa sensação por meio dos recursos que the são disponíveis, isto é, reage com o corpo, defecando e chorando. Salientamos que dessa resposta corporal, o paciente se faz perceber pelos pais, que o olham assustados. O paciente/bebê, então, com sua resposta corporal, "nasce", ganha vida na cena, passa a fazer parte desta.

Há aqui, portanto, a marcação freudiana sobre a existência de um momento de organização subjetiva que se estabelece pela via corporal/identificatória e não pela via simbólica permitida pela aquisição da linguagem. Simultaneamente, o que Freud marca também é que traços desse modo de organização não são jamais perdidos e se re-atualizam ao longo da vida do paciente. Isso porque a cena em questão ocorre em um momento em que o paciente/bebê se encontra identificado com sua mãe. Nessa identificação percebemos algo que sai da mãe (o pênis paterno) e algo que sai do bebê (as fezes). A sensação prazerosa, que ambos sentem nesse momento, marca uma trilha somato/psíquica. Vemos essa trilha ser retomada pelo paciente/bebê, paciente/menino, paciente/homem, descrita ao longo do 
texto freudiano. Neste, destacamos três pontos que nos parece princeps daquilo que desejamos apontar como representativo desse trilhamento soma/psique que sustentará seu adoecimento psicossomático em torno dos intestinos:

- o apelo do paciente de estar com sangue nas fezes diante da ameaça de uma disenteria que poderia levar as pessoas à morte;

- a declaração do paciente sobre a sensação de estar vivo após a aplicação dos enemas que o faziam defecar intensamente e em quantidade;

- a fantasia de re-nascimento construída pelo paciente sustentada no rompimento do capuz que o encobria ao nascer.

Destacamos que nesses momentos podemos visualizar algo que remete o paciente ao estágio primitivo de seu desenvolvimento emocional e ao modo de organização psíquica correspondente sobre o qual um adoecimento psicossomático em torno dos intestinos se configura. Mas, para darmos suporte a nossas argumentações, recorremos aqui à perspectiva winnicottiana. Autor que entende os fenômenos psicossomáticos como relativos a um momento de desenvolvimento subjetivo arcaico, anterior ao Édipo e à possibilidade da linguagem poder exercer sua função simbólica.

\section{DA CENA À DISSOCIAÇÃo PSIQUE/SOMA}

Para Winnicott (1990a), os fenômenos psicossomáticos assinalam os primeiros rudimentos de uma paulatina integração entre soma e psique que deverá permanecer ao longo da vida. Assim, tal fenômeno só se expressará como um adoecimento se indicar uma ameaça a essa integração. Ou seja, pensar em adoecimentos psicossomáticos para Winnicott é pensar em um movimento de defesa extrema contra uma ameaça de desorganização subjetiva.

Para compor sua teorização sobre a integração soma/psiquê, Winnicott parte da hipótese sobre a existência de um momento inicial de constituição subjetiva em que o bebê humano se apresenta em um completo estado de dependência em relação a um ambiente. Nesse momento, totalmente incapaz de satisfazer por si mesmo uma série de necessidades somáticas que clamam por satisfação, o bebê necessita radicalmente de um outro para tal. Para garantir a sobrevivência de um bebê, há, portanto, que existir um ambiente/ mãe que o acolha e satisfaça, a tempo e a hora, suas necessidades básicas. Em correspondência, uma série de vivências corporais dispersas, e não interligadas entre si, se sucedem inúmeras vezes inscrevendo-o no diferencial desprazer/prazer.

Para Winnicott (2000[1956]), será justamente a repetição constante dessas experiências de satisfação aquilo que vai permitindo a ocorrência de uma paulatina integração a não-integração original. O processo de integração se estabelece em dois níveis de registro: um corporal, no qual as sensações suscitadas vão se remetendo umas às outras de forma a dar substrato a um contorno corporal; e um nível psíquico na medida em que tais experiências vão recebendo sentidos e significações afetivas e emocionais a partir dos cuidados maternos. Nesse rastro, os 
trilhamentos psíquicos vão sendo constituídos em paralelo e em concomitância às sensações corporais. Razão pela qual, para o autor, tal processo se configura como os rudimentos iniciais de uma progressiva inserção da psique no soma. $\mathrm{Ou}$ seja, se configura como o início de uma trama psico-somática que deverá perdurar ao longo de nossas vidas e funcionar de forma organizada, sustentando a nossa sensação de continuarmos existindo, isto é, que nosso corpo se fez morada para nosso Ser. (WINNICOTT, 2000 [1949])

Dessa forma, tal movimento refere-se a um estágio de desenvolvimento subjetivo marcado por um lado pelas sensações corporais que se ligam a rudimentos afetivos e sensoriais que se tornarão, ao longo do tempo, psíquicos. Esse movimento é, portanto, relativo a um momento de dependência absoluta, sustentado por uma completa identificação com a mãe/ambiente, no qual as sensações e vivências se sistematizam pela via corporal.

Porém, nos alerta o autor, por tratar-se de uma trama, de uma organização em constante movimentação e re-arranjos, pode haver momentos em que tal integração sofra abalos que a tensionem ao rompimento. Rompimento que para Winnicott (1990b) significa uma forma radical de adoecimento quer seja do corpo puro ou da psique em dissociação. Nessa perspectiva, o adoecimento psicossomático é entendido como uma defesa contra a desintegração das malhas psicossomáticas que se efetivada nos lançaria ao encontro da dependência absoluta e à dissociação psique/soma.

Tais considerações nos sustentam em nossa proposição que, no caso do homem dos lobos descrito por Freud foi esse o movimento que permitiu a eleição dos intestinos como local privilegiado de organização das sensações vivenciadas. Tal movimento tornou os intestinos um ponto privilegiado de afecção psicossomática que o acompanhou ao longo de toda sua vida. Importa salientar que esse momento arcaico de desenvolvimento subjetivo relativo à dependência absoluta é marcado, como diz Winnicott (1990a), pela problematização da "Existência". Dessa forma, nesse momento, o que está em questão é a possibilidade de se estar "vivo" ou "não vivo", ou seja, para o bebê nesse estágio, a questão primeira é de vida ou de morte e só posteriormente se apresenta em termos sexuais edipianos, "ser homem" ou "ser mulher".

Na cena reconstruída por Freud e seu paciente, este/bebê "nasce" no momento em que defeca e chora, é nesse momento que ele "ganha vida" para os pais, para Freud e para nós leitores. Somente nesse momento ele começa a fazer parte da cena, torna-se vivo, torna-se um personagem em movimentação, em relação.

Winnicott nos oferece os instrumentos conceituais para pensarmos que desses rudimentos vivenciais primitivos, uma malha, uma trama psico/somática se inicia e proporciona ao bebê a sensação contínua de estar vivo, de possuir um corpo que inicia sua jornada no campo das relações humanas. O interessante é vermos que tal movimento subjetivamente arcaico é acionado pelo paciente ao longo de sua vida em momentos em que sua existência se vê ameaçada. Citamos como exemplo dois entre esses momentos: 1- quando o paciente ouve comentários sobre a existência de uma disenteria que poderia o levar à morte, ele responde 
identificando-se com sua mãe e apresentado sangue nas fezes; 2 - o momento em que o paciente vai perdendo o sentido de sua existência, vai se tornando sem sentido, se sentindo "morto", ele novamente recorre à identificação materna e, ao receber de um homem enemas, descarrega intensamente os intestinos. Nesses momentos, diz o paciente a Freud, ele tem a sensação de estar vivo, de realmente existir. Fantasia de re-nascimento que nesse paciente passa pela ruptura de um capuz que o encobria ao nascer e que o "expulsa" do corpo materno, tal como fezes e que o concede, enfim, a vida.

Se Freud pôde perceber os traços neuróticos nessas manifestações destacando e pontuando os elementos histéricos e obsessivos destes, acreditamos que com os elementos fornecidos por Winnicott podemos ir um pouco mais além e destacarmos, igualmente, traços psicossomáticos que se estabelecem como uma defesa recuperada pelo paciente em momentos chaves de sua vida em que se encontra diante de um impasse quanto à sua "Existência". Enfrentar a questão que a ele se impôs inúmeras vezes, isto é, "estar" ou "não estar vivo", é respondida pela via do adoecimento psicossomático. Se, por um lado, essa manobra defensiva o mantém prisioneiro de uma trama sem solução, por outro aponta para uma positividade ao permitir que a organização alcançada não se desfaça e que as malhas psicossomáticas ainda possam ser mantidas fornecendo-lhe sustentação para continuar a viver (going on being). Ainda em contato consigo mesmo.

\section{Apenas Para CONCluir}

Iniciamos nosso percurso circunscrevendo o objetivo central de nossos estudos no alcance de uma compreensão teórica que nos permita enfrentar os impasses que a escuta das patologias do corpo vêm nos impondo no exercício de nossa clínica cotidiana. Com essa intenção, nos servimos de um caso clínico apresentado por Freud para fazer valer nossa hipótese de que o mesmo fenômeno clínico pode ser compreendido de diferentes maneiras dependendo do suporte teórico que se toma como referência. Nesse trajeto, o que nos movimentou não foi a possibilidade de apontarmos um suposto equívoco por parte de Freud, mas o de sublinharmos que encontramos nas teorizações de Freud e de Winnicott elementos fundamentais para pensarmos as relações entre soma e psique que se expressam, no espaço analítico de diversas formas e maneiras. Intrumentalizar a clínica dependerá dos recursos teóricos que nos estão disponíveis no momento da produção de nosso ofício. O interessante é percebermos que se Freud estava empenhado em entender os mecanismos psíquicos das psico-neuroses (histeria e neurose obsessiva) tal fato não o impediu de abrir portas fundamentais para o entendimento de outras patologias. Vimos, nesse texto como o autor se aproxima das vivências primitivas de constituição subjetiva em seu trabalho com o Homem dos Lobos. Percebemos como ele se refere a esse momento como anterior ao recalque e, portanto, anterior ao drama Edípico. Importa salientar que sendo assim, esse movimento é referente a um momento de constituição subjetiva primitiva referente a um modo de organização subjetiva arcaico para além do registro lingüístico. Freud percebe, então, que estaria lidando clínicamente com elementos que não se referindo ao recalcado inconsciente não seriam passiveis de serem re- 
cordados por meio da interpretação. Impasse clínico que se estabelece à interpretação e para o qual o autor responde, criativamente, propondo outro instrumento clínico: a construção. Ou seja, diante do que há em nós de mais primitivo e não inscrito no registro lingüístico, diante do abismo que nos constitui como sujeitos desejantes, paradoxalmente, ali onde não há palavras, Freud responde indo adiante e construindo uma cena. Cena repleta de personagens, de movimentos, de afetos, de infinitos desdobramentos.

Acreditamos que seja sobre essas bases teóricas abertas por Freud que Winnicott sustentará, posteriormente, seu percurso. Aprofundando as considerações sobre esse momento fundador da subjetividade e sobre esse posicionamento clínico. Pois, se em Freud temos, sem dúvidas, um privilégio da palavra e da simbolização, encontramos, igualmente, uma abertura flagrante ao indizível e incompreensível. Posicionamento que Winnicott adotará como fundamento para a clínica das afecções psicossomáticas posto que, para o autor, a clínica desses adoecimentos se estabelece na possibilidade do analista ofertar um acolhimento às sensações corporais que se apresentam no espaço da clínica e permitir, a partir do não passível de ser dito, que algum contorno e integração possa ser alcançado.

Não é interessante encontrarmos tais fundamentos, também, no texto freudiano?

\section{REFERÊNCIAS}

FREUD, S. Sobre os fundamentos para destacar da neurastenia uma síndrome específica denominada neurose de angústia (1895). In: . Obras Psicológicas Completas de Sigmund Freud. Rio de Janeiro: Imago, 1976. v. 3, p. 56-63. Edição Standard Brasileira.

FREUD, S. Obsessões e Fobias: seu mecanismo psíquico e sua etiologia (1894). In:_ Obras Psicológicas Completas de Sigmund Freud. Rio de Janeiro: Imago, 1976, v.3, p.33-42. Edição Standard Brasileira.

FREUD, S. Fragmentos da análise de um caso de histeria (1904). In: Obras Psicológicas Completas de Sigmund Freud. Rio de Janeiro: Imago, 1976, v. 7, p. 23-76. Edição Standard Brasileira.

FREUD, S. Análise de uma fobia em um menino de cinco anos (1909). In:

Obras Psicológicas Completas de Sigmund Freud. Rio de Janeiro: Imago, 1976, v .10, p. 23-76. Edição Standard Brasileira.

FREUD, S. História de uma neurose infantil (1918). In: Obras Psicológicas Completas de Sigmund Freud. Rio de Janeiro: Imago, 1976, v. 16, p.12-123. Edição Standard Brasileira.

WINNICOTT, D. Localização da psique no corpo. In: . Natureza Humana. Rio de Janeiro: Imago, 1990a. p.143-146. 
WINNICOTT, D. Reconsiderando a questão psicossomática. In: Natureza Humana. Rio de Janeiro: Imago, 1990b. p. 181-185.

WINNICOTT, D. A preocupação materna primária (1956). In: . $D a$ pediatria à psicanálise - Obras escolhidas. Rio de Janeiro: Imago, 2000. p. 7782.

WINNICOTT, D. A mente e suas relações com o psicossoma (1949). In:

Da pediatria à psicanálise - Obras Escolhidas. Rio de Janeiro: Imago, $\overline{2000, \mathrm{p}}$. 77-82.

Recebido em: 14 de julho de 2009 Aceito em: 21 de outubro de 2011 